\title{
CORRIGENDUM
}

\section{Conscientiousness and externalizing psychopathology: Overlap, developmental patterns, and etiology of two related constructs}

BRENT W. ROBERTS,${ }^{a}$ JOSHUA J. JACKSON,${ }^{a}$ JESSICA M. BERGER,${ }^{a}$ AND ULRICH TRAUTWEIN ${ }^{b}$

${ }^{a}$ University of Illinois, Urbana-Champaign; and ${ }^{b}$ University of Tubingen and Max Planck Institute for Human Development, Berlin

The third author's name was misspelled in the original version of this article. The authors regret this error and any problems it may have caused. 